Design of Civil Environmental Engineering

\title{
Structural form of bridges reflecting construction processes
}

\section{Yusuke Mizuno}

Nippon Engineering Consultants CO., LTD., Japan

mizuno@ne-con.co.jp

\section{Yoshiaki Kubota}

University of Toyama, Japan

k.ubota@sus.u-toyama.ac.jp

\begin{abstract}
The structural form of a bridge during construction is strongly affects its structural form after completion, with innovative construction processes sometimes leading to innovative bridge designs. It is thus important to consider the construction process during bridge design methods. This approach could be applied not only to new construction but also to replacements, reconstructions, or reinforcements. One of the authors has previously systematized the structural forms of bridges and clarified the principles. This study aims to extend these principles to construction systems. Changes in the structural systems of the construction processes and systematization of the relationship between a completed bridge and construction process in a design are illustrated. Three types of structural systems (suspension, beam, and arch systems) were analysed in terms of material efficiency and time efficiency for corresponding construction states of construction, completed, retrofitted, and retrofitting. Each system exhibited different levels of efficiency at different levels of efficiency at different states of construction. This systematization enables the application of a variety of conventional construction methods in a system. This would be helpful in developing new construction methods and designs for bridges.
\end{abstract}

KEYWORDS. Systematization; Construction Process; Innovative Bridge Design.

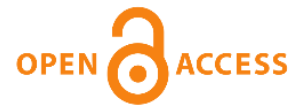

Citation: Mizuno, Y., N., Kubota, Y., N., Structural Form of Bridges Reflecting Construction Processes, Frattura ed Integrità Strutturale, 47 (2019) 209-220.

Received: 29.07 .2018

Accepted: 29.11.2018

Published: 01.01.2019

Copyright: (C) 2019 This is an open access article under the terms of the CC-BY 4.0, which permits unrestricted use, distribution, and reproduction in any medium, provided the original author and source are credited.

\section{INTRODUCTION}

he structural form of a completed bridge is strongly affected by its structural form during construction. As such, innovative construction processes sometimes produce innovative bridge designs. It is important to consider the construction process in conjunction with bridge design methods. For example, Kingsgate Bridge (Fig. 1) in Durham, 
the UK, which was designed by Sir Ove Nyquist Arup, elegantly represents the construction process of the bridge in the completed form. During the construction of this bridge, bents and scaffoldings were not used in order to protect the river ecosystem. Instead, each half of the bridge, which comprised a concrete V-shaped rigid frame pier and beam, was constructed at each bank of the river on a cylindrical foundation parallel to the river. The parts were then rotated by $90^{\circ}$ to form the complete bridge. This is an example of an outstanding design approach where the construction process led to the invention of a new construction method that solved a specific problem at the site. Furthermore, the resulting bridge is a fine-looking structure.

In this manner, the design approach, which also considers the construction process, could be applied not only to new constructions but also to replacements, reconstructions, or reinforcements.

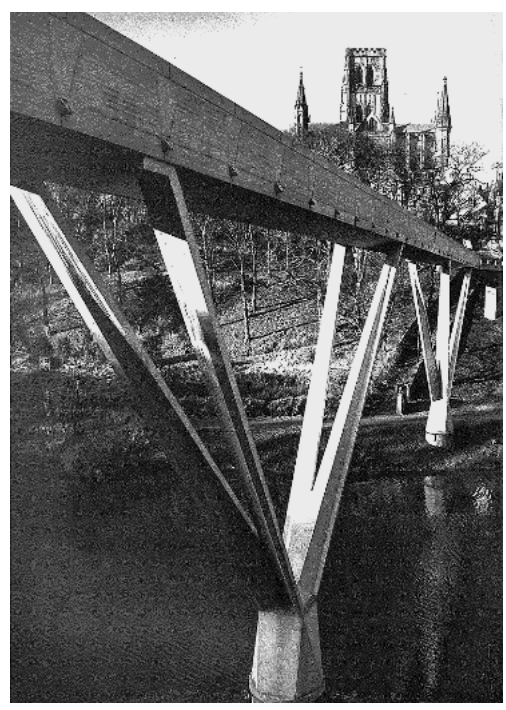

Figure 1: King's Gate Bridge [1].

\section{BACKGROUND AND PURPOSE OF RESEARCH}

$\mathrm{R}$ esearchers such as Frei Otto, Mike Schlaich, and others have advanced the systematization of structures. Frei Otto [2] organized a lightweight structure in a book titled "Form and Structure". Mike Schlaich [3], organized a lightweight structure in a book titled "Shape and Structure". One of the authors of this paper, Kubota [4], has systematized the structural forms of bridges and clarified their underlying principles on the basis of the types of forces acting on bridge members. To date, research has mainly focused on the structural forms of completed bridges.

This study aims to extend Kubota's method to include the construction systems. In this research, changes in the structural systems during the construction processes and systematization of the relationship between a completed bridge and construction process in a design are illustrated.

\begin{tabular}{cccccc}
\hline Acting force & 1 dimension & 2 dimensions & 3 dimensions & $\begin{array}{c}\text { Typical } \\
\text { Structural systems }\end{array}$ & $\begin{array}{c}\text { Fundamental } \\
\text { bridge types }\end{array}$ \\
\hline Tension force & $*$ & $*$ & $*$ & Suspension system & $\begin{array}{c}\text { Suspension } \\
\text { bridge }\end{array}$ \\
Compression force & $*$ & $*$ & $*$ & Arch system & Arch bridge \\
Bending moment & $*$ & $*$ & $\begin{array}{c}\text { Beam system } \\
\text { (Web system) }\end{array}$ & Birder \\
Shear force & $*$ & $*$ & Beam system & Truss bridge \\
Torsional moment & & $*$ & & - &
\end{tabular}

Table 1: Dimensions of acting forces, structural systems, and fundamental bridge types [5]. 


\section{BASIC THEORY}

7 his work relies on Kubota's [4] previous research, which describes the form of fundamental bridge types and force acting upon them. A new method is developed to elucidate the transition of structural forms in the construction process.

\section{RELATIONSHIP BETWEEN FORCE AND FORM OF FUNDAMENTAL BRIDGE TYPES}

G enerally, five types of forces can be imposed on a bridge. These can be classified as follows according to the dimensions of the space where they can exist: axial force, that is, tension and compression, for one dimension; bending moment and shearing force for two dimensions; and torsional moment for three dimensions. Tab. 1. shows the forces acting on a bridge, dimensions that the forces that can exist within, typical structural systems that resist these forces, and corresponding fundamental bridge types. As ordinary bridges are usually constructed to cross at a right angle to obstacles, such as rivers, roads, or railways, and cross straight to the other side, torsional moment seldom becomes a major factor when selecting the bridge type. Thus, torsional moment does not correspond to any of the structural systems and bridge types in this table. In practical applications, there are obviously more bridge types. In addition, the forces acting on a real bridge are more complicated as several types of forces often act simultaneously on a member. However, it is important to understand that the dominant force imposed on a structure has a great influence on the form of the bridge. Therefore, this analysis pairs four bridge types (suspension, arch, girder, and truss) with their corresponding forces.

The abovementioned four fundamental bridge types are related to each other, and the relationships are illustrated in Fig. 2. There are six combinations of two bridge types.

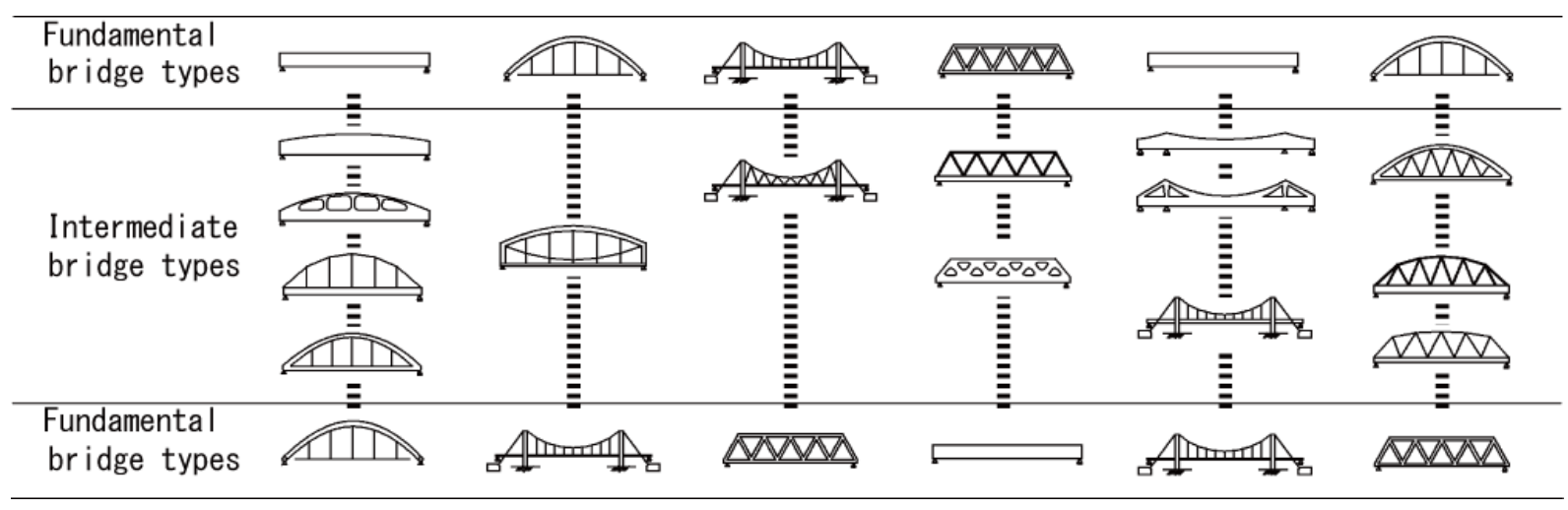

Figure 2: Continuous relationships between fundamental bridges [5].

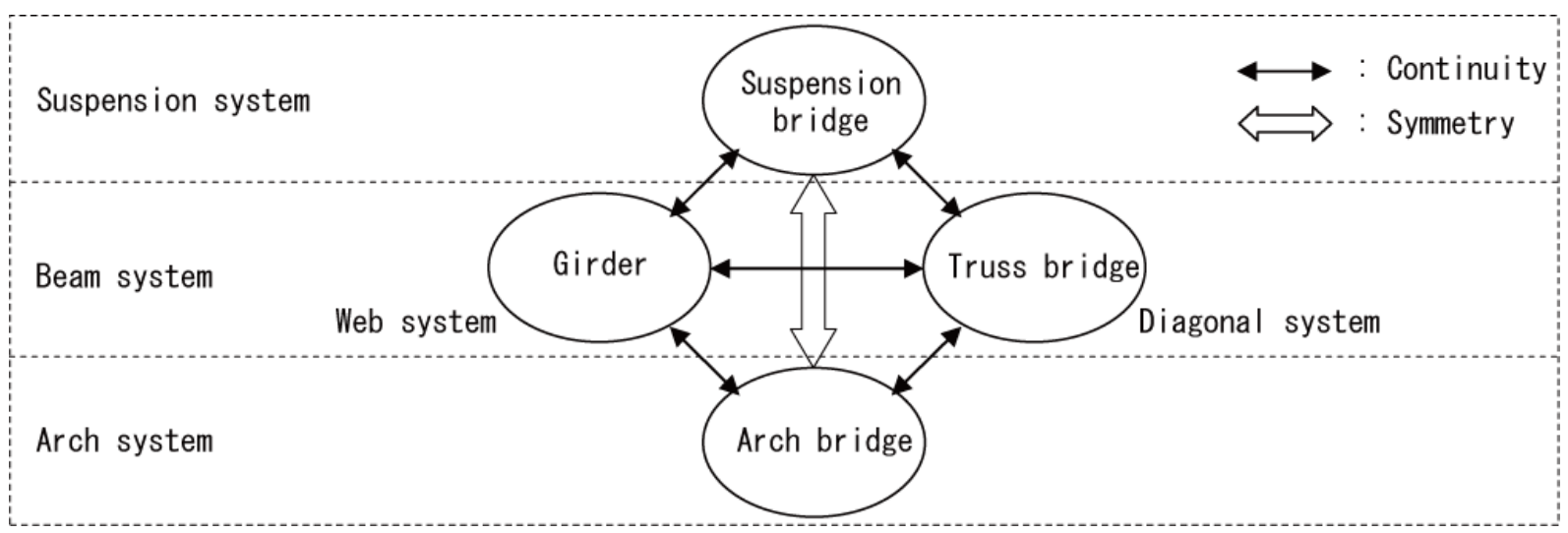

Figure 3: Interrelationships among four fundamental bridge types [5].

In this figure, the relationship between the suspension bridge and arch bridge is expressed as continuity. However, it could also be expressed as symmetry. Fig. 3 illustrates the interrelationships among the four fundamental bridge types related to 
the acting forces. In this figure, the relationships between the four fundamental bridge types are integrated into a diagram with six arrows indicating the continuity or symmetry in structure and form among them. This figure also shows three classifications of structural systems: a suspension system, beam systems, and an arch system.

We can consider not only the linear relationships shown in Fig. 3, but also more complex relationships among the various bridges. The relationships shown in Fig. 3 are altered to obtain two (upper and lower) triangular coordinate systems with bilateral symmetry in Fig. 4. Furthermore, the vertical position of the main structure and the floor system is illustrated in the depth direction of the figure. A bridge consisting of a suspension system, a web system, and a diagonal system is shown in the upper half of the figure (triangular prism S1G1T1-S3G3T3), while a bridge consisting of an arch system, a web system, and a diagonal system is shown in the lower half of the figure (triangular prism A1T1G1-A3T3G3). Bridges that have a symmetrical relationship in structure and form would be placed at symmetrical points with respect to the central plane (G1T1T3G3), as shown in Fig. 4.

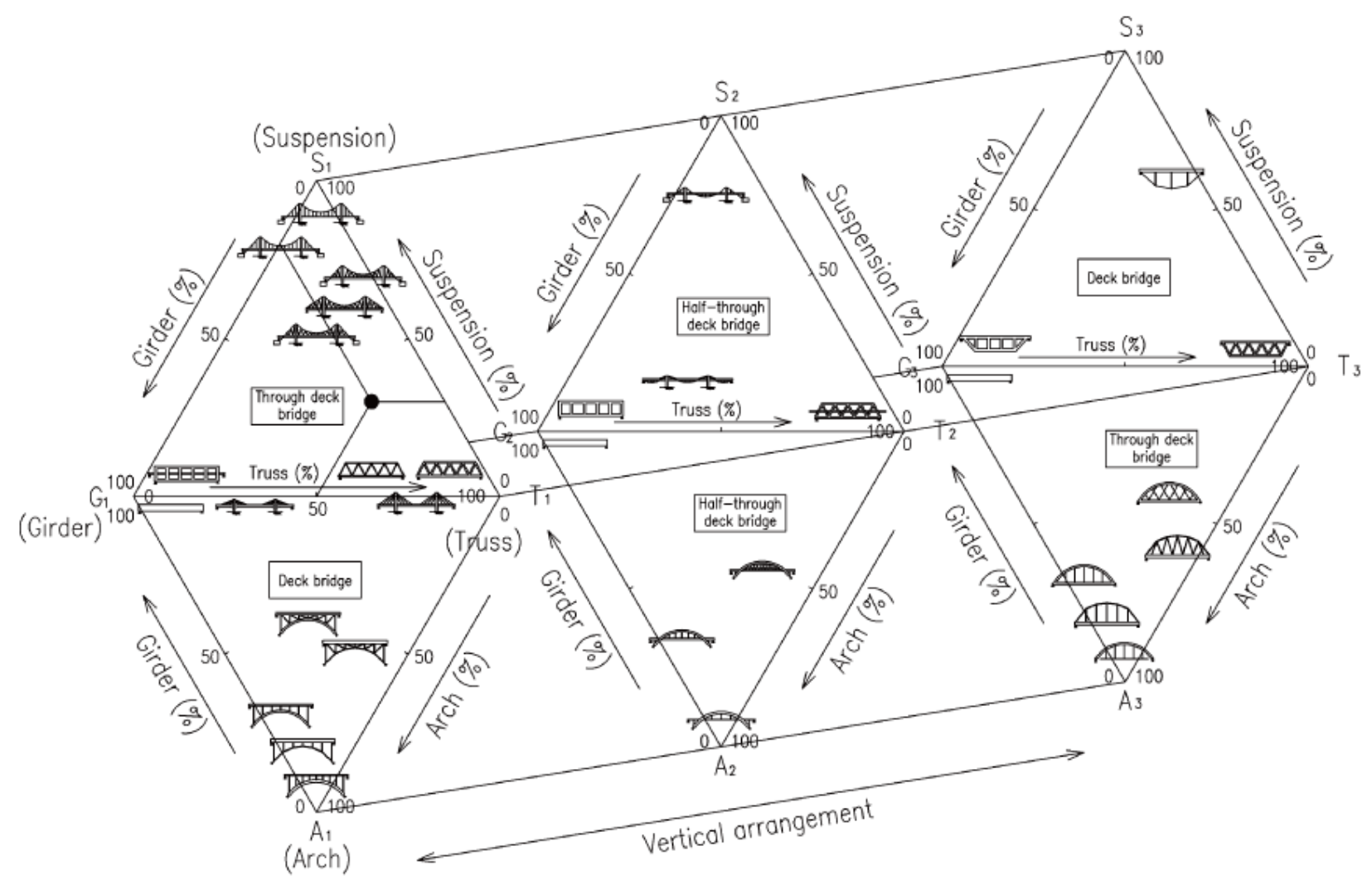

Figure 4: Correlation chart expressed by triangular coordinate systems [5].

\section{TRANSITION OF STRUCTURAL FORM}

he structural form changes during the life cycle of a bridge (Fig. 5). In this study, the states are separated into three parts: construction state, completed state, and retrofitted state. Furthermore, retrofitting is defined as a new structural system applied to an existing structure.

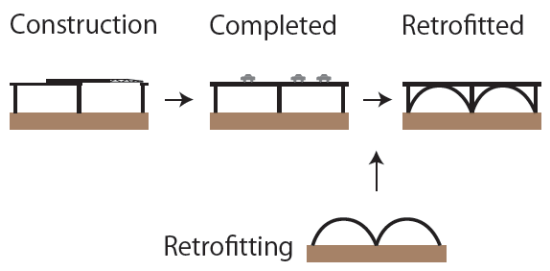

Figure 5: Transition of structural form in a typical life cycle of a bridge. 


\section{CLASSIFICATION OF ELEMENTS OF TRANSITION OF STRUCTURAL FORM}

coordinate system for a bridge incorporates movement, which occurs during the construction of the bridge. This $A$ is described by a combination of six degrees of freedom in three-dimensional space (Fig. 6). The $x$-axis is the 1 bridge's axial direction, the $\mathrm{y}$-axis is the direction in a horizontal plane at right angles to the $\mathrm{x}$-axis, and the $\mathrm{z}$-axis is the vertical direction. The coordinate origin is set at the point where the rotation of the structural system is the simplest on the $\mathrm{x}$-axis. Rot-x can support small rotations such as when the structure supports a dead load, but this ability decreases drastically as the rotation angle becomes large. Rot-y is effective in beam systems, but it cannot achieve the cantilever status in spanning system (suspension and arch). Therefore, its support base, such as suspension tower and bearing, moves vertically. Rot-z can occur only in a beam system (diagonal system structure and web system structure) because it can become a cantilever system.

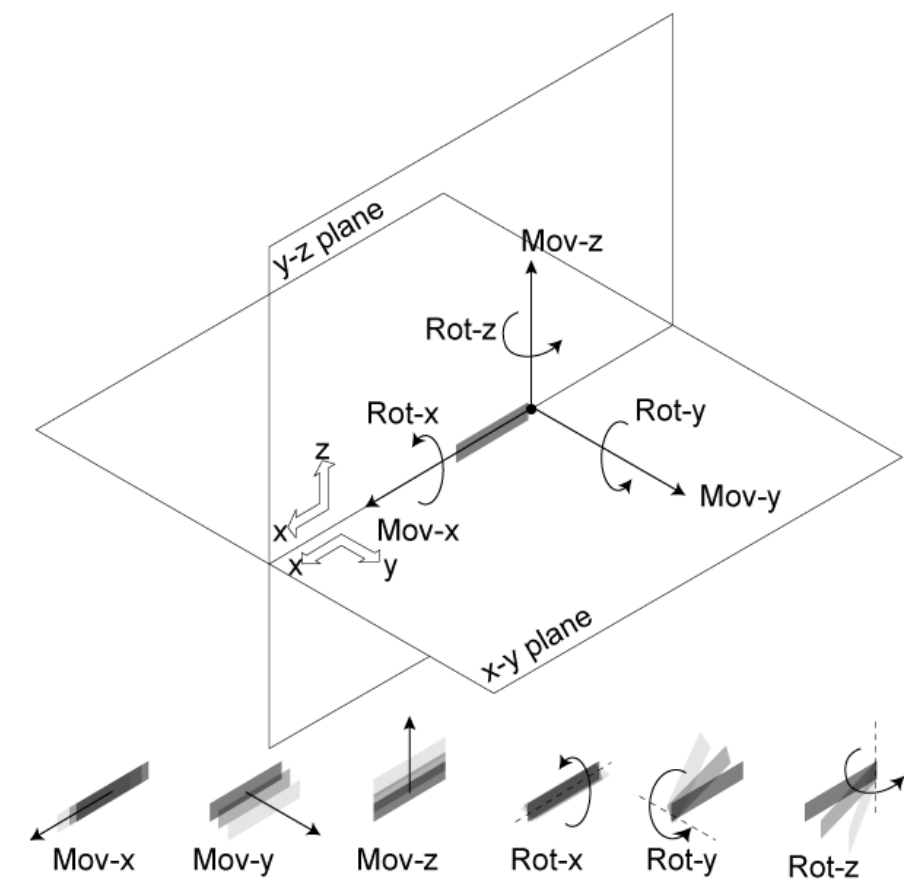

Figure 6: Movement and rotation of the bridges.

The element variations of structures include four typical structural systems are shown in Tab. 2. First, the structural condition of bridges is classified into the "spanning system" and "cantilever system" (Tab. 2). Then, the "spanning system" is classified into the free rotation condition (Rot) and fixed rotation condition (Fix) of the end point in the y-z plane. This classification can describe typical structural conditions of bridges, such as simple structure, consecutive structure, bothends-fixed structure, and cantilever structure. Thus, all structural conditions can be described in the area enclosed by a heavy line in Tab. 2. Basic transitions of structural form in the construction process can be explained as a combination of them.

\begin{tabular}{|c|c|c|c|c|c|c|c|c|c|c|}
\hline \multirow{3}{*}{\multicolumn{2}{|c|}{ The Elements }} & Spani & ystem & \multirow{3}{*}{$\begin{array}{c}\text { Cantilever } \\
\text { System }\end{array}$} & \multirow{3}{*}{ Mov-x } & \multirow{3}{*}{ Mov-y } & \multirow{3}{*}{ Mov-z } & \multirow{3}{*}{ Rot-x } & \multirow{3}{*}{ Rot-y } & \multirow{3}{*}{ Rot-z } \\
\hline & & \multicolumn{2}{|c|}{ Boundary Condition } & & & & & & & \\
\hline & & Rot & Fix & & & & & & & \\
\hline \multicolumn{2}{|c|}{ Suspension System } & $\mathrm{O}$ & $x$ & $x$ & $x$ & O & O & $\triangle$ & $\triangle$ & $x$ \\
\hline \multirow{2}{*}{ Beam System } & Web System & $\mathrm{O}$ & $\mathrm{O}$ & $\mathrm{O}$ & $\mathrm{O}$ & $\mathrm{O}$ & $\mathrm{O}$ & $\triangle$ & $\mathrm{O}$ & $\mathrm{O}$ \\
\hline & Diagonal System & $\mathrm{O}$ & $\mathrm{O}$ & $\mathrm{O}$ & $\mathrm{O}$ & $\mathrm{O}$ & $\mathrm{O}$ & $\triangle$ & $\mathrm{O}$ & $\mathrm{O}$ \\
\hline \multicolumn{2}{|c|}{ Arch System } & 0 & $\times(*)$ & $x$ & $x$ & 0 & 0 & $\triangle$ & $\triangle$ & $x$ \\
\hline
\end{tabular}

- $\bigcirc$; avilable, $\times$; unavilable, $\Delta$; aviilable under the specific condition

- Though arch bridge can transfer bending moment at the endpoints because of the bending rigidity, column $\left(^{*}\right)$ is filled with "I" because a pure arch system can transmit only axial compression force.

Table 2: Adaptability to spanning/cantilever systems and movement within six degrees of freedom. 


\section{ANALYSIS OF EXAMPLES}

\section{Illustration method of transition of structure}

7 he four coloured shapes from the triangular coordinate system correspond to four types of life cycle states.

Members in the construction, completed, retrofitted, and retrofitting states are shown in light blue, magenta, orange, and purple, respectively. The construction process proceeds from left to right. We examined six examples of construction processes illustrated below.

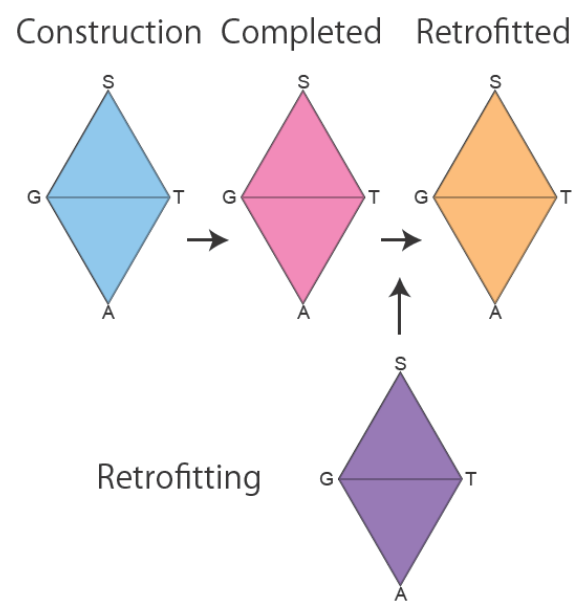

Figure 7: Construction states (G, S, T, A mean Girder, Suspension, Truss, Arch).

\section{Single-operation Method of the Suspension Bridge (Fig. 8)}

This construction method involves an innovative idea in the construction process. When hung up, temporary compression diagonal members enable the structure to function as a cantilever truss balanced at both endpoints. After it is set, the cables, which are left at both the endpoints, are fixed at the anchor while the structure is hung up. As the temporary diagonal members are removed, the structural system becomes the suspension system. Thus, the structure supporting the dead load changes from the cantilever system to the suspension system. This bridge needs few temporary diagonal members to function as it is made of fibre reinforced plastic. Thus, this method is an example of a simple, single-operation method for small and medium sized bridges using only one crane. Furthermore, the design is innovative and aesthetic. This design hides the pylons in the trees and vegetation such that drivers under the bridge can see only the slender bridge girder.

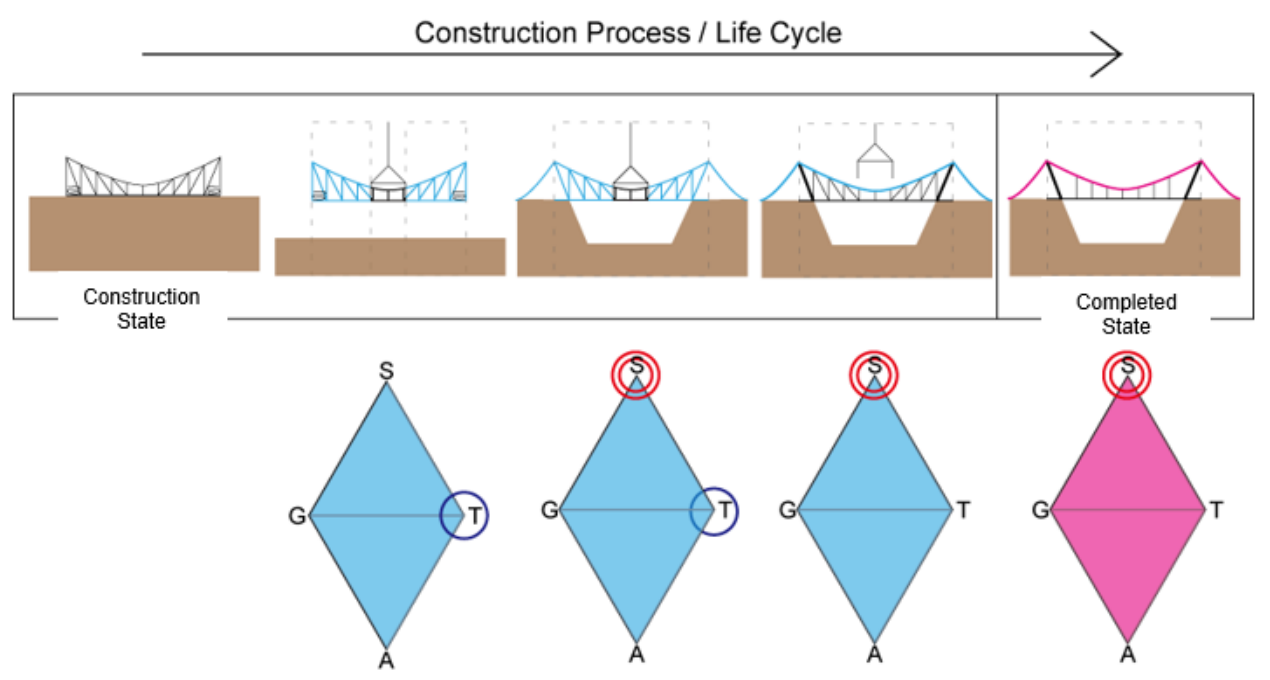

Figure 8: Single-operation method of the suspension bridge (Halgavor Footbridge [6]).

Construction of the Dischinger-Type Bridge (Fig. 9)

At first, cable-stayed bridges are constructed to overhang from the pylons. The bridge is designed as a diagonal system, the truss system. Then, the pylons for making the cable-stayed bridge are used for the exact purpose as for suspension cables. 
In this manner, live load and dead load of the floor construction beam are supported by the combination of a cable-stayed system as one of the truss systems and a suspension system. In this method, there are no large temporary support structures. Thus, this method is efficient because of material efficiency and is suitable for long bridges. This Dischinger method is currently the best method for constructing long span bridges. Although the cables visually clash with each other and appear complicated at the spot where both structural systems overlap, the completed bridge appears light because many cables are used in the cable-stayed system and suspension system.

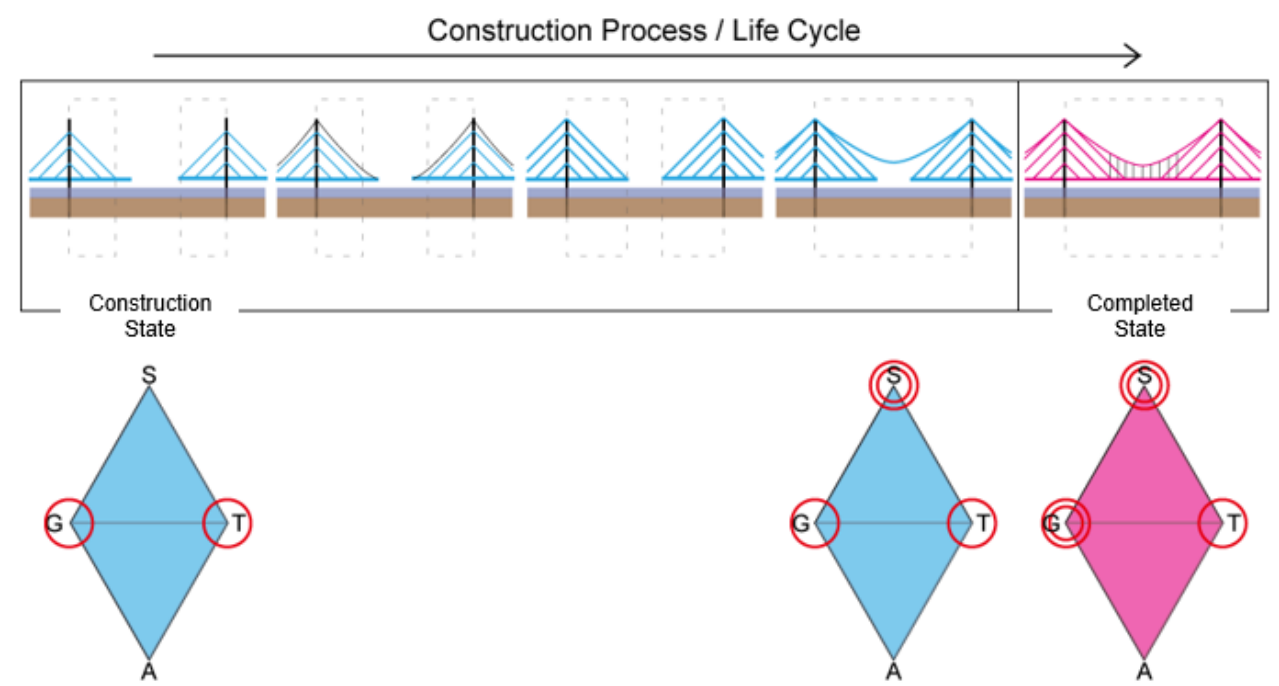

Figure 9: Construction method of the Dischinger-type bridge (The Yavuz Sultan Bridge [7]).

\section{Lowering Method (Fig. 10)}

In the lowering method, precast arch rib members are rotated on hinges installed on both banks, which eventually make up the arch system. In the rotation process, cables receive reaction force from outside the system and arch rib members constitute a cantilever truss system, which resemble triangles. The truss system changes its stress state during the rotation process. Finally, the arch rib members are closed and function as an arch system. This method features good the material efficiency because no huge temporary support structure is used during construction. However, the axial force occurring in the arch rib members during the rotation process is converted into the bending moment because their shape bends in relation to the arch structure. Thus, this method is not suitable for very long bridges because the truss system is not structurally efficient. Almost nothing from the rotation process remains in the construction state. Nevertheless, stress analysis is necessary for every angle because internal stress changes along with the form change of the truss structure.

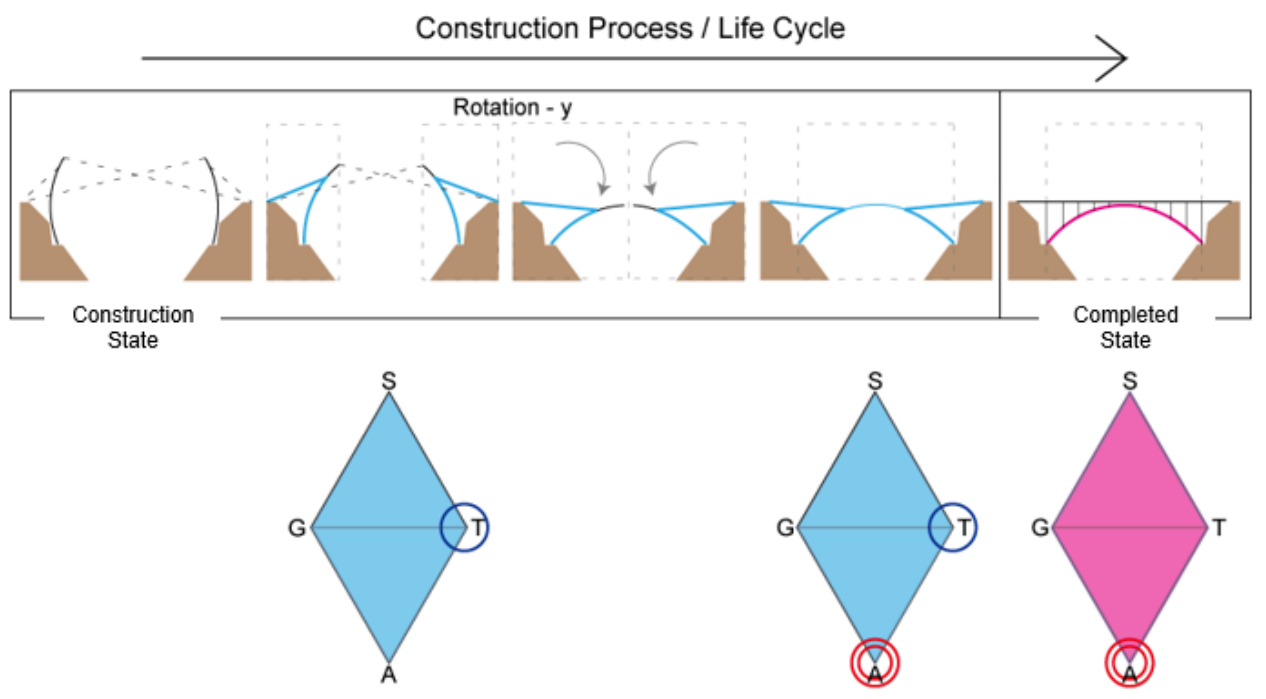

Figure 10: Lowering method [8]. 
Horizontal Rotation Method (Fig. 11)

Kingsgate Bridge is a pedestrian bridge over the River Wear that Ove Arup regarded as his life's masterpiece. As explain earlier, V-shaped half parts, rigid frame pier and beam, were constructed on cylindrical foundations parallel to the river. The parts were then rotated by $90^{\circ}$ and connected. During construction, the two V-shaped structures functioned as a cantilever truss system. Then, the final structural form took shape through rotation-z on the cylindrical foundation. The extremely slender $\mathrm{V}$-shaped pier gives the bridge an elegant and delicate appearance.

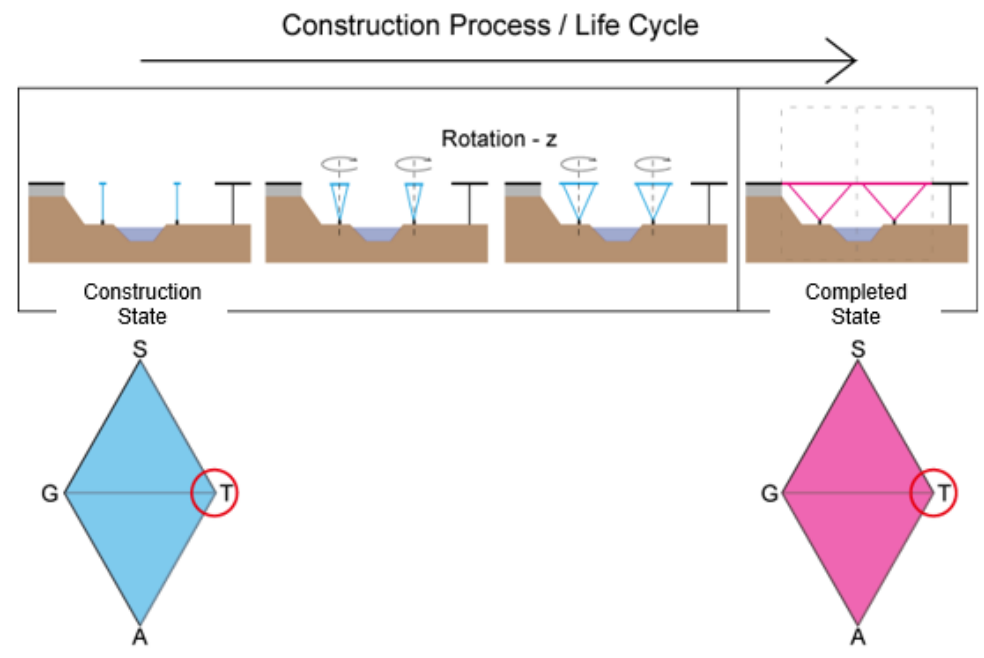

Figure 11: Horizontal rotation method (Kingsgate Bridge [1]).

Vertical Cable Erection Method (Fig. 12)

In this method, two types of suspension cables are employed in the construction state. Carrier cables transport blocks of bridge members and main cables hang vertically. After the truss bridge (the final structure) is completed, hanger ropes are removed and the dead load is transferred from a suspension system to a diagonal system-the truss system. This method requires many temporary structures, such as pylons, carrier cables, and main cables; however, there are many variations of structural forms in the completed state because the main cables work as falsework, taking all loads.

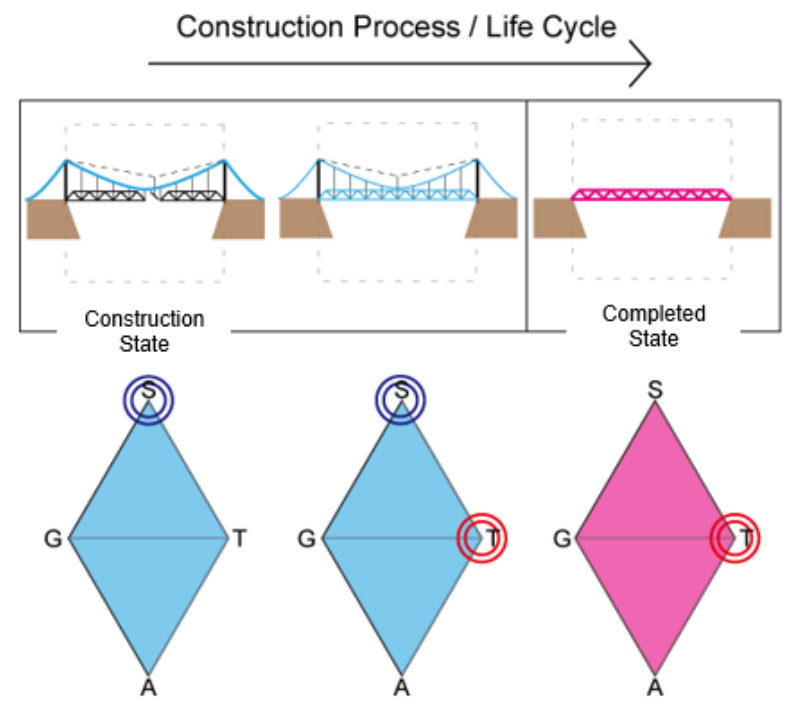

Figure 12: Vertical cable erection method [9].

Reinforcement by Retrofitting the Middle Hinge PC Bridge with String Beam Structure (Fig. 13)

The rigid-frame middle hinge bridges, which were constructed frequently during the period of high economic growth in Japan, has a striking deflection at the hinge located in middle of the span. Therefore, this method was used for restoring it. The bending moment at the hinge point is zero and the floor construction beam overhangs both endpoints beyond the 
post. Therefore, the span, which includes the repair part, is regarded as two cantilever girders butted against each other. Thus, the final structure system is a retrofitted cantilever girder with the spanning system.

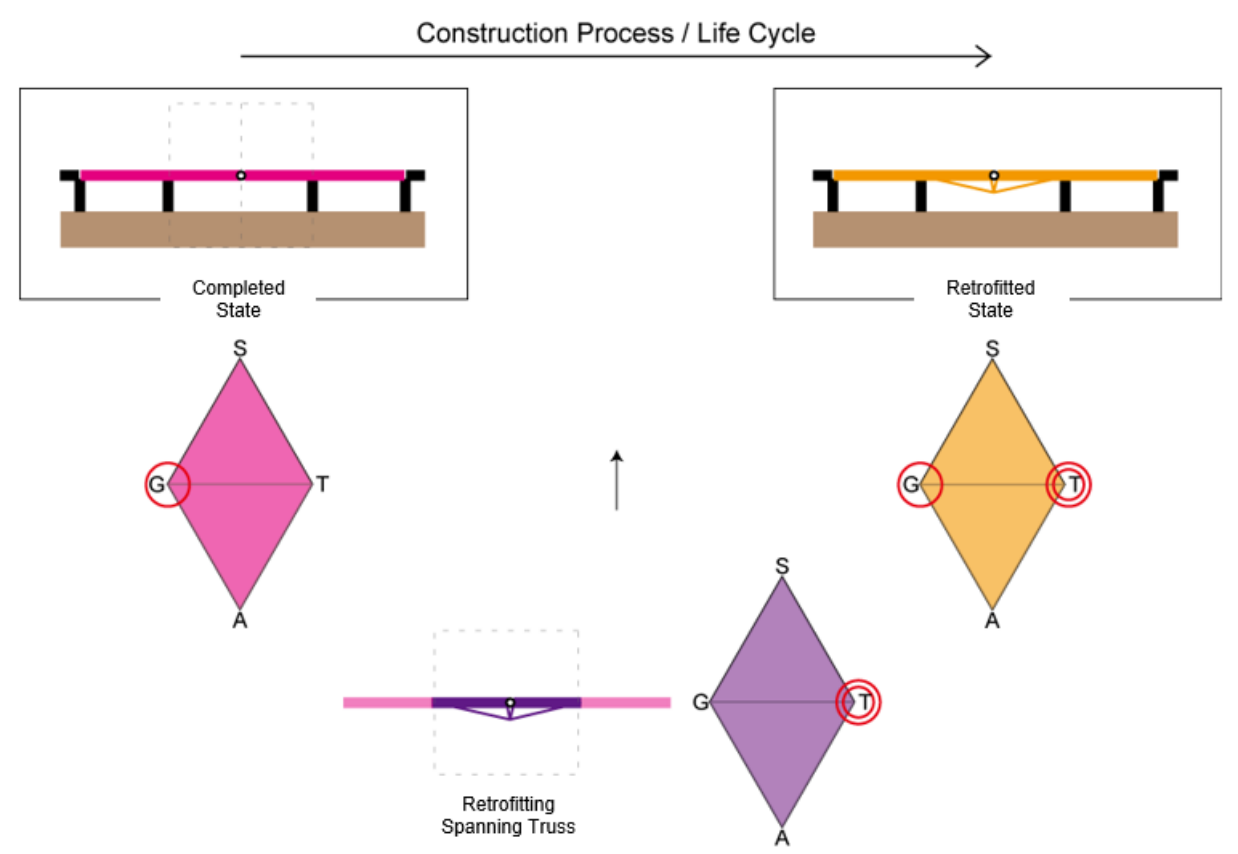

Figure 13: Reinforcement by retrofitting the middle hinge of a PC bridge with string beam structure (Kireuriwari Bridge [10]).

\section{EVALUATION OF THE APPLICABILITY AND EFFICIENCY OF STRUCTURAL SYSTEMS}

7 he lifecycle of brides involve many construction types, including new construction, reinforcement, repair, and removal. New construction is a basic construction type used to consider all other types. Structural changes that occur in new constructions are shown in Tab. 4 and Tab. 5. (Note: Tab. 4 and Tab. 5 are presented separately to avoid spacing issues). We analysed the "Applicability of Structural System", which indicates the likelihood that a structural system will change to another system and "Efficiency of Material and Time" for Tab. 4 and Tab. 5.

\section{Applicability of Structural System}

The vertical cable erection method, which uses a suspension system, can be used to construct almost all types of bridges. The diagonal cable erection method or overhanging erection method, which use a diagonal system, can be applied to many types of bridges, such as arch bridges, cable-stayed bridges, and truss bridges. Using the special construction methods of the "Halgavor Footbridge" suspension bridges can also be constructed with a diagonal system. In this respect, a suspension system and a diagonal system have high potential for constructing various types of bridges. On the other hand, while a web system can be used in the launching method as a beam system, the applicability of that structural system is comparatively low. An arch system is rarely used in the construction state. However, the applicability of a suspension system and a diagonal system in the construction state is particularly high.

\section{Material Efficiency}

Bridges that do not undergo changes in their structural system from the construction to the completed state throughout the cycle, such as a suspension bridge or a cable-stayed bridge, have high material efficiency because they do not require massive temporary structures.

\section{Time Efficiency}

Bridges using a beam system have high time efficiency because they can be placed using parallel translation such as the launching-type erection method. In addition, a beam system can be hung up by a small number of cranes. However, these methods generally require many temporary structures in the construction state. Accordingly, material efficiency tends to be low. Nevertheless, attempts can be made to improve material efficiency by using temporary structures several times. 


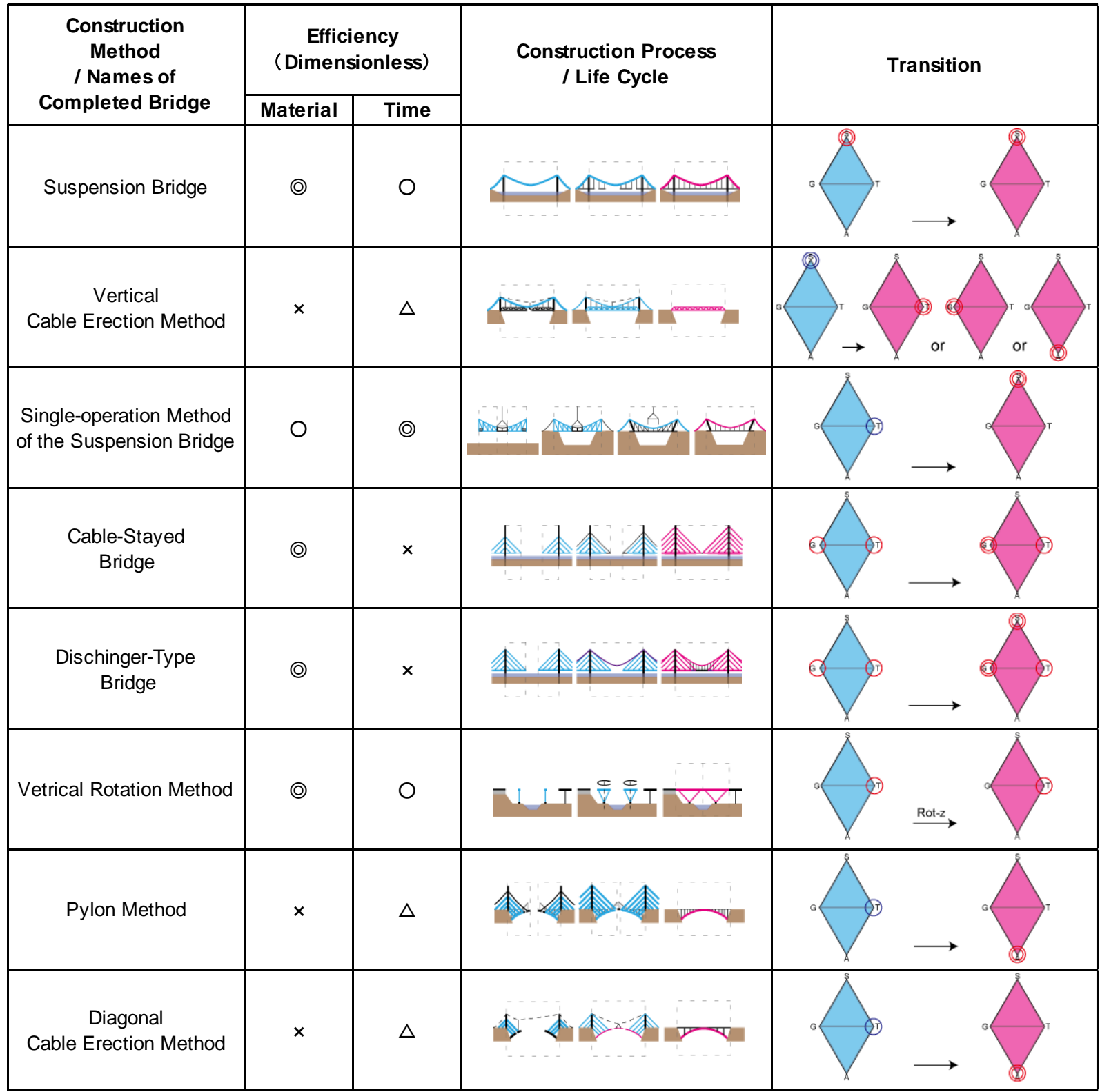

Table 4: Structural change list No.1 for newly constructed bridges.

\section{EFFICIENCY UNDER DIFFERENT CONDITIONS}

Ab. 6 compares the efficiency between three types of structural systems, including a suspension system, a beam system, and an arch system, with corresponding construction states of construction, completed, retrofitted and retrofitting. The suspension system generally exhibits good material efficiency, but the efficiency is low in the retrofitted state, because of the difficulty of reinforcement. It is difficult to maintain the cable as a series of elements in order to conduct the reinforcement in such a manner that the tension force is not interrupted but flows to the end portion. The beam system has better material efficiency because it requires a small number of temporary structures for the advantage of cantilevering. In addition, time efficiency can be improved by using the launching-type erection method. It functions well in the construction state, and it is efficient in the retrofitting state if a diagonal system is used for stiffening. The arch system is not efficient in the construction state because it is not easy to build without support from another system. However, in the retrofitting state, it is efficient for reinforcing existing structures. The arch system can accept various types of reinforcement in the retrofitted state because countermeasures, such as rolling up reinforcement, can be easily taken afterwards. 


\begin{tabular}{|c|c|c|c|c|}
\hline \multirow{2}{*}{$\begin{array}{c}\text { Construction } \\
\text { Method } \\
\text { / Names of } \\
\text { Completed Bridge }\end{array}$} & \multicolumn{2}{|c|}{$\begin{array}{c}\text { Efficiency } \\
\text { (Dimensionless) }\end{array}$} & \multirow[t]{2}{*}{ Construction Process } & \multirow[t]{2}{*}{ Transition } \\
\hline & Material & Time & & \\
\hline Lowering Method & O & $\triangle$ & & \\
\hline $\begin{array}{c}\text { Overhanging } \\
\text { Arch Erection Method } \\
\text { with Truss }\end{array}$ & 0 & $x$ & & \\
\hline $\begin{array}{l}\text { Arch Center } \\
\text { Method }\end{array}$ & $x$ & O & & \\
\hline $\begin{array}{c}\text { Balanced Cantilever } \\
\text { Method }\end{array}$ & () & $\triangle$ & & \\
\hline $\begin{array}{l}\text { Launching } \\
\text { Erection Method }\end{array}$ & $\Delta$ & () & & \\
\hline $\begin{array}{c}\text { Span by Span } \\
\text { Construction Method }\end{array}$ & $x$ & (2) & & \\
\hline $\begin{array}{l}\text { Single-Operation Method } \\
\text { with Floating Crane or } \\
\text { Pontoon }\end{array}$ & $x$ & (2) & & \\
\hline $\begin{array}{c}\text { Fixed Timbering Erection } \\
\text { Method }\end{array}$ & $x$ & (2) & 111 & \\
\hline
\end{tabular}

Table 5: Structural change list No. 2 for newly constructed bridges.

\begin{tabular}{|c|c|c|c|c|c|c|}
\hline \multicolumn{3}{|c|}{$\begin{array}{c}\text { Triangular } \\
\text { Coordinate System }\end{array}$} & Constructed & Completed & Retrofitted & Retrofitting \\
\hline \multicolumn{2}{|c|}{$\begin{array}{l}\text { Suspension System } \\
\text { (Spanning System) }\end{array}$} & \multirow{3}{*}{$G \backslash$} & $\begin{array}{c}\text { Efficient } \\
\text { because of the } \\
\text { material efficiency }\end{array}$ & $\begin{array}{c}\text { More efficient } \\
\text { because of the } \\
\text { material } \\
\text { efficiency }\end{array}$ & Low efficiency & $\begin{array}{c}\text { Efficient } \\
\text { because of the } \\
\text { material } \\
\text { efficiency }\end{array}$ \\
\hline $\begin{array}{l}\text { Web System } \\
\text { (Beam System) }\end{array}$ & $\begin{array}{c}\text { Diagonal } \\
\text { System } \\
\text { (Beam System) }\end{array}$ & & $\begin{array}{c}\text { Efficient at both } \\
\text { time and material } \\
\text { because of being } \\
\text { used as a } \\
\text { cantilever }\end{array}$ & $\begin{array}{c}\text { Efficient } \\
\text { because of the } \\
\text { material } \\
\text { efficiency }\end{array}$ & Efficient & $\begin{array}{c}\text { Efficient } \\
\text { if being used as } \\
\text { a diagonal } \\
\text { system }\end{array}$ \\
\hline \multicolumn{2}{|c|}{$\begin{array}{c}\text { Arch System } \\
\text { (Spanning System) }\end{array}$} & & Low efficiency & $\begin{array}{c}\text { More efficient } \\
\text { because of the } \\
\text { material } \\
\text { efficiency }\end{array}$ & Efficient & $\begin{array}{l}\text { Efficient for } \\
\text { Supporting } \\
\text { exisiting } \\
\text { spanning } \\
\text { systems }\end{array}$ \\
\hline
\end{tabular}

Table 6: Effectiveness in each structure system. 
Thus, in the construction state, the suspension system is the most efficient system and the arch system is the most inefficient system from the aspect of material quantity. In contrast, in the retrofitted state, the suspension system is the most inefficient system and the arch system is the most efficient system from the aspect of material property. The superiority of each structural system is dependent upon whether it is a new construction or reinforced structure.

\section{CONCLUSION}

I n this study, we established an analysis method based on a "Structural Form Correlation Chart", which showed the change of structural form throughout the life cycle of bridges including construction processes. We then systematized the relationships between the structural forms in the completed state and construction processes including retrofitting existing bridges. In addition, we revealed the peculiarities of four fundamental structural systems such as the applicability of structural systems and the efficiency of material and time corresponding to the three states of construction, completed, and retrofitted. We will improve this theory in future studies to develop innovative construction processes and bridge designs while focusing on more example analyses in a quantitative manner.

\section{REFERENCES}

[1] Mikami, Y. (1996). Kenchiku Shiryo Kenkyusha CO., LTD., Zokei in Japanese, pp. 74-81.

[2] Frei, O. (1976). Form and Structure. Harper Collins Distribution Services.

[3] Schlaich, M. (2006). Challenges in Education-Conceptual and Structural Design IABSE Symposium Report, IABSE Symposium, Budapest 2006: Responding to Tomorrow's Challenges in Structural Engineering, pp. 20-26.

[4] Kubota, Y. (2009). Fundamental Study on the Method Used for the Operations on the Structure and Form of a Bridge, J. Japan Soc. Civ. Eng., 65(1), pp. 64-76.

[5] Kubota, Y. (2010). Systematization of structures and forms of truss systems, 34TH International Symposium on Bridge and Structural Engineering, pp. 1-5.

[6] Firth, I. and Cooper, D. (2018). New Materials for New Bridges-Halgavor Bridge, UK, Struct. Eng. Int., 12(2), pp. 80-83.

[7] IABSE (2016). The Yavuz Sultan Selim Bridge, Turkey. Available at:

[8] https://www.iabse.org/IABSE/association/Award_files/Outstanding_Structure_Award/YSSB_Turkey.aspx

[9] Sato, T., Kaneko, K., and Kajima K. (2013). Adoption of the Lowering Construction Method of Raise type RC Fixed Arch Bridge Takatakinozawa Bridge in Japanese, The 57th Hokkaido Development Technology Research Presentation.

[10] Otsuka, S., Minami, D., Yoshida, M., Kondo, H., Miyama, Y., and Shibuya, D. (2017). Design and Construction of make more Rationalized Truss by Sandwich Composite Slab: Nagatani Bridge, Bridge and Foundation Engineering, 51(3), pp. 25-30.

[11] Suzuki, T., Wakatsuki, K., and Manabe, H., Nishi, H. (2004). Reinforcement Design and Construction of Kireuriwari viaduct-Confirmation of Reinforcement Effect of Hinge Ramen Bridge using Lower String Cables in Japanese, Proceedings of Symposium on the Development of Prestressed Concrete 13, pp.45-54. 